\title{
Urethral Dosage Form
}

National Cancer Institute

\section{Source}

National Cancer Institute. Urethral Dosage Form. NCI Thesaurus. Code C69052.

A substance intended for administration into the urethra. 